\title{
PENGARUH OUTBOUND MANAGEMENT TRAINING TERHADAP POTENSI ORGANISASI (Studi pada Pegawai Bank Indonesia Surabaya)
}

\author{
Budi Sudjijono \\ Fakultas Ekonomi \\ Universitas Islam Indonesia
}

\begin{abstract}
Abstrak
Sumber daya manusia sebagai sumber daya strategis merupakan potensi organisasi yang wujud dasarnya adalah budaya kerja dalam bentuk nilai-nilai atau sikap. Potensi organisasi (budaya kerja, nilai, sikap) harus selalu dikembangkan agar meningkatkan kinerja organisasi dalam mencapai visi, misi dan tujuan BI.

Pelatihan merupakan proses yang efektif ketika organisasi ingin menciptakan/mengembangkan sikap pegawai yang sesuai untuk menghadapi perubahan. Sikap yang diperoleh lewat pengalaman menimbulkan pengaruh langsung terhadap perilaku berikutnya, dan situasi yang bebas akan memunculkan perilaku aktual sebagai cerminan sikap yang sesungguhnya. Outbound Management Training (OMT) sangat cocok digunakan sebagai pelatihan pengembangan sikap karena penggunaan metode belajar lewat pengalaman dan diselenggarakan di alam bebas agar memberi suasana bebas tanpa tekanan. Pengukuran pembelajaran dalam pelatihan menjadi salah satu permasalahan, agar OMT bisa lebih efektif untuk mengembangkan sikap. Penelitian ini bertujuan untuk mengkaji/mengetahui penggunaan OMT sebagai media pelatihan untuk meningkatkan potensi organisasi (sikap pegawai).

Potensi organisasi dalam hal ini nilai/sikap pegawai BI mengenai komitmen kepada tugas, keterbukaan dalam bersikap, kecakapan dalam bekerja, kebersamaan dalam hubungan sosial dan integritas pribadi yang tinggi, dijadikan variabel terpengaruh dan digunakan sebagai dasar untuk menguji apakah OMT sebagai intervensi individu/kelompok mampu meningkatkan/mengembangkan potensi pegawai. setelah OMT.

Penelitian menunjukkan bahwa potensi pegawai mengalami perubahan meningkat yang signifikan
\end{abstract}

Kata kunci: Outbound Management Training, Potensi Organisasi.

\section{LATAR BELAKANG}

Di awal abad 21 perekonomian dunia menunjukkan perkembangan yang mengarah pada tercapainya perdagangan bebas. Perkembangan baru ini semakin didorong oleh pertumbuhan teknologi informasi yang berkembang dengan pesat sehingga memungkinkan terjadinya paperless transction, penyebaran informasi dalam waktu yang teramat singkat, dan kegiatan-kegiatan global lainnya yang mengubah dunia menjadi kawasan tanpa batas.

Kondisi tersebut di atas mempengaruhi perekonomian Indonesia yang dapat dirasakan antara lain: a). Arus modal yang mudah keluar ataupun masuk ke wilayah Indonesia, b). Globalisasi perbankan yang menuntut perbankan nasional meningkatkan 
profesionalisme dalam meningkatkan daya saingnya (Budaya Kerja BI, 1999).

Perkembangan tersebut mengakibatkan Bank Indonesia menghadapi tugas yang semakin berat terutama karena perubahan struktur sistem keuangan Indonesia dan tuntutan penguasaan ilmu pengetahuan dan teknologi. Hal ini menuntut Bank Indonesia untuk menyesuaikan arah organisasi dan Manajemen Sumber Daya Manusia agar mampu menghadapi tantangan masa depan.

Potensi pegawai Bank Indonesia (BI) merupakan suatu hal yang penting, bahkan kunci dalam pencapaian Kinerja BI. Pegawai BI akan memberikan segala yang ada pada dirinya (potensi diri) untuk disumbangkan secara lebih demi tercapainya visi, misi dan tujuan BI. Potensi akan menampakkan menjadi tindakan nyata jika telah menjadi suatu sikap pada diri manusia. Sikap pegawai BI yang menjadikan perhatian dalam penelitian ini adalah sikap terhadap nilai-nilai:

Komitmen, Keterbukaan, Kecakapan, Kebersamaan dan Integritas pegawai BI (Budaya Kerja BI, 1999).

Penelitian ini menekankan pengukuran/penilaian pegawai mengenai potensi/sikap sebelum mengikuti pelatihan dan pengembangan (Outbound Management Training-OMT) dengan sesudah mengikuti OMT, pada masing-masing pegawai yang sama, dengan menggunakan Uji Wilcoxon Matched Pairs dan Pairs $t$ test. Mengetahui apakah masingmasing pegawai $\mathrm{BI}$ meningkat potensi/sikapnya (komitmen, keterbukaan, kecakapan, kebersamaa dan integritas) sesudah mengikuti OMT perlu dan penting untuk melihat kegunaan dan efektivitas OMT serta dalam rangka kebijakan peningkatan pencapaian kinerja BI dalam mencapai visi, misi dan tujuan BI.

\section{PERUMUSAN MASALAH}

Masalah penelitian ini diturunkan dari masalah/pertanyaan manajemen: bagaimana meningkatkan potensi pegawai Bank Indonesia, dan dengan intervensi melalui "Outbound Management Training (OMT)" apakah potensi pegawai Bank Indonesia dapat ditingkatkan.

Dengan demikian masalah dalam penelitian ini adalah: bagaimana hubungan Outbound Management Training terhadap potensi organisasi, dan apakah Outbound Management Training BI dapat meningkatkan potensi pegawai $\mathrm{BI}$. 


\section{TUJUAN PENELITIAN}

Mendasarkan pada perumusan masalah, maka yang menjadi tujuan dari penelitian ini adalah: menganalisis hubungan OMT terhadap potensi organisasi, dan mengkaji potensi organisasi yang dipengaruhi oleh OMT.

\section{MANFAAT PENELITIAN}

Dari penelitian yang dilakukan diharapkan dapat diperoleh manfaat: memahami hubungan/kegunaan OMT dengan peningkatan potensi organisasi, memahami bahwa potensi organisasi dapat ditingkatkan melalui intervensi OMT, menyediakan Informasi bagi organisasi/perusahaan sebagai pertimbangan dalam merancang program peningkatan potensi organisasi/perusahaan.

\section{TINJAUAN PUSTAKA DAN HIPOTESIS}

\section{Organisasi Bank Indonesia}

Agar BI tetap dapat mengemban visi dan misi sebagai Bank Sentral, yakni menciptakan stabilitas moneter, industri perbankan nasional yang sehat, dan sistem pembayaran yang aman dan terpercaya maka Bank Indonesia menetapkan strategi organisasi dalam bentuk strategic thrust yang memuat visi dan strategic focus untuk mencapai visi tersebut. Visi $\mathrm{BI}$ adalah menjadi lembaga terpercaya dan disegani dalam bidang pengendalian moneter; bidang pengaturan, pembinaan dan pengawasan bank; serta bidang sistem pembayaran. Untuk mencapai visi tersebut, perlu ditempuh langkah-langkah untuk menjadikan Bank Indonesia sebagai :

- organisasi yang dapat menjadi model (contoh) peran manajemen yang baik (management role model).

- Organisasi yang memiliki kompetensi tinggi sesuai dengan standar internasioal (internationally competent) (Budaya Kerja BI 1999).

Dimana Keberhasilan $\mathrm{BI}$ dalam pencapaian visi menuntut adanya penyempurnaan organisasi serta perumusan budaya kerja.

Penyempurnaan organisasi diarahkan untuk mewujudkan BI menjadi organisasi yang efektif, yaitu organisasi yang mampu memenuhi kepentingan para pihak yang terkait (stakeholder) dan mampu mencapai goalnya secara efektif dan efisien.

Untuk dapat mencapai goal organisasi secara efektif dan efisien diperlukan kerja sama yang sinergis antar unsur-unsur pokok organisasi yang terdiri atas 7S Mc. Kensey (Starategy, Structure, System, Skills, Style, Staff, dan Shared Value). 
Dari uraian di atas terlihat bahwa pencapaian visi organisasi dan pembentukan organisasi yang efektif dipengaruhi juga oleh budaya kerja yang kondusif (shared value). Sehubungan dengan hal tersebut, kiranya potensi/sikap pegawai $\mathrm{BI}$ memegang peranan kunci.

\section{Potensi/Sikap Pegawai Bank Indonesia}

Sumber daya manusia (SDM) merupakan sumber daya strategis dalam organisasi/perusahaan. Pada diri SDM tersimpan sebuah potensi yang sangat berpengaruh dalam perilaku dan bekerja; potensi tersebut adalah nilai/sikap yang dimiliki. Pada setiap organisasi/perusahaan akan memiliki sebuah formulasi nilai/sikap yang disepakati dan diyakini yang menghasilkan seperangkat norma yang mempengaruhi pola pikir dan perilaku dalam bekerja sebagai pegangan dalam menjalankan kewajiban/tugas.

Sikap manusia, atau untuk singkatnya disebut sikap didefinisikan oleh Allen dkk (1980):

'suatu pola perilaku, tendensi atau kesiapan antisipatif, predisposisi untuk menyesuaikan diri dalam situasi sosial, atau secara sederhana, sikap adalah respons terhadap stimuli sosial yang telah terkondisikan'.

Sedangkan menurut Secord dan Backman (1964):

Sebagai 'keteraturan tertentu dalam hal perasaan (afeksi), pemikiran (kognisi), dan predisposisi tindakan (konasi) seseorang terhadap suatu aspek di lingkungan sekitarnya'.

Sikap dikatakan sebagai suatu respon evaluatif. Respon hanya akan timbul apabila individu dihadapkan pada suatu stimulus yang menghendaki adanya reaksi individual. Respon evaluatif berarti bahwa bentuk reaksi yang dinyatakan sebagai sikap itu timbulnya didasari oleh proses evaluasi dalam diri individu yang memberi kesimpulan terhadap stimulus dalam bentuk nilai baik-buruk, positif-negatif, menyenangkan-tidak menyenangkan, yang kemudian mengkristal sebagai potensi reaksi terhadap objek sikap. Akankah potensi reaksi itu akhirnya dinyatakan dalam bentuk reaksi perilaku yang konsisten atau sesuai bila individu dihadapkan pada stimulus sikap.

Menurut Breckler dan Wiggins (1989):

"bahwa sikap yang diperoleh lewat pengalaman akan menimbulkan pengaruh langsung terhadap perilaku berikutnya".

Pengaruh langsung lebih berupa predisposisi perilaku yang akan direalisasikan hanya apabila kondisi dan situasi memungkinkan. Kondisi apa, waktu apa, dan situasi bagaimana saat individu tersebut harus 
mengekspresikan sikapnya merupakan sebagian dari determinandeterminan yang sangat berpengaruh terhadap konsistensi antara sikap dengan pernyataannya dan antara pernyataan sikap dengan perilaku.

Apabila individu berada dalam situasi yang betul-betul bebas dari berbagai bentuk tekanan atau hambatan yang dapat mengganggu ekspresi sikapnya maka dapat diharapkan bahwa bentuk-bentuk perilaku yang ditampakkannya merupakan ekspresi sikap yang sebenarnya. Artinya, potensi reaksi yang sudah terbentuk dalam diri individu itu akan muncul berupa perilaku aktual sebagai cerminan sikap yang sesungguhnya terhadap sesuatu.

Dalam pencapaian visi/misi organisasi/perusahaan akan efektif bila ada integrasi antara visi, misi, tujuan, strategi struktur dan budaya organisasi/kerja. Budaya kerja atau nilai/sikap sebagai sebuah potensi organisasi/perusahaan sebaiknya memiliki formulasi yang sederhana dan jelas sehingga mudah dipahami oleh setiap pegawai dan dapat diterapkan dalam organisasi/perusahaan.

\section{Outbound Management Training}

Outbound Management Training merupakan sebuah metode pengembangan diri melalui pengalaman (learning by experience) sebagai salah satu bentuk aktivitas luar ruang (outdoor activities) yang penuh dengan kegembiraan dan tantangan. Efektivitas pelatihan dicapai melalui lima tahapan proses, yaitu aksi, diskusi, refleksi, perencanaan perbaikan dan implementasi.

Adapun tujuan dari pelatihan Outbound adalah untuk membantu peserta memperoleh karakter, sehingga mereka dapat memberikan kontribusi baik secara pribadi maupun sebagai anggota dari satu tim kerja.

Outbound Management Training mempunyai sasaran untuk menjadikan pembangunan sumber daya manusia yang tangguh, bermartabat dan sikap yang kokoh dengan berlandaskan pada empat nilai utama, yaitu profesionalisme, inovasi, patriotisme dan cinta alam dengan sasaran utama Pengembangan dan Pemberdayaan Sumber Daya Manusia. Manfaat OMT bagi peserta/partisipan akan memberikan peningkatan/pengembangan potensi diri (sikap, wawasan, daya inovasi, kepemimpinan, kerjasama tim dan kepercayaan diri).

\section{HIPOTESIS}

Secara konseptual OMT sebagai bentuk intervensi individual/kelompok sangat tepat untuk memecahkan masalah penelitian ini, sekaligus sebagai jawaban sementara untuk meningkatkan potensi/sikap. Untuk itu dalam penelitian ini diajukan hipotesa penelitian: 
"Outbuond Management Training dapat meningkatkan potensi pegawai BI Surabaya mengenai nilai/sikap komitmen, keterbukaan, kecakapan, kebersamaan dan integritas".

Selanjutnya dari hipotesis di atas diturunkan hipotesa kerja yang akan digunakan untuk proses pembuktian kebenaran hipotesa penelitian:

- $\mathrm{H}_{0}=$ Pelatihan OMT BI tidak mempunyai pengaruh yang berarti terhadap potensi organisasi.

- $\mathrm{H}_{1}=$ Pelatihan OMT BI mempunyai pengaruh yang berarti terhadap potensi organisasi

\section{METODE PENELITIAN}

Jenis penelitian yang digunakan dalam penelitian ini adalah "desain yang diacak dengan sempurna", yang merupakan ekstensi dari desain eksperimental sejati dengan pola sebagai berikut.

$\begin{array}{llll}\mathrm{R} & \mathrm{O}_{1} & \mathrm{X}_{1} & \mathrm{O}_{2} \\ \mathrm{R} & \mathrm{O}_{3} & \mathrm{X}_{3} & \mathrm{O}_{4} \\ \mathrm{R} & \mathrm{O}_{5} & \mathrm{X}_{5} & \mathrm{O}_{6} \\ \mathrm{R} & \mathrm{O}_{7} & \mathrm{X}_{7} & \mathrm{O}_{8} \\ \mathrm{R} & \mathrm{O}_{9} & \mathrm{X}_{9} & \mathrm{O}_{10} \\ \mathrm{R} & \mathrm{O}_{11} & \mathrm{X}_{11} & \mathrm{O}_{12}\end{array}$

$\mathrm{R}$ mengidentifikasikan bahwa anggota-anggota kelompok telah ditempatkan secara acak kedalam kelompok, artinya dalam kelompok selalu terdiri dari berbagai bagian, seksi, urusan yang ada dalam struktur organisasi $\mathrm{BI}$ Surabaya (anggota kelompok tidak dari satu bagian/seksi/urusan saja). $\mathrm{O}_{1}, \mathrm{O}_{3}, \mathrm{O}_{5}, \mathrm{O}_{7}, \mathrm{O}_{9}$ dan $\mathrm{O}_{11}$ mengidentifikasi pengukuran sebelum stimulus perlakuan berupa Outbound Management Training dengan "pra test" pada angkatan I, II, III, IV, V dan VI.

$X_{1}, X_{3}, X_{5}, X_{7}, X_{9}$, dan $X_{11}$ menunjukkan stimulus dengan berbagai perlakuan fasilitator yang terlibat sebagai pelatih, kehadiran pimpinan $\mathrm{BI}$ Surabaya sebagai fasilitator $\mathrm{BI}$ guna menghubungkan materi pelatihan dengan dunia kerja dan kehadiran pimpinan $\mathrm{BI}$ pusat Jakarta. $\mathrm{O}_{2}, \mathrm{O}_{4}, \mathrm{O}_{6}$, $\mathrm{O}_{8}, \mathrm{O}_{10}$, dan $\mathrm{O}_{12}$ mengidentifikasi pengukuran sesudah stimulus perlakuan dengan "pasca test" pada angkatan I, II, III, IV, V dan VI.

Karena jumlah populasi tidak begitu banyak (250 pegawai $\mathrm{BI}$ Surabaya) dan juga mengingat penelitian ini merupakan kasus pada BI Surabaya saja, maka semua pegawai BI Surabaya menjadi responden (tidak menggunakan sampling tapi sensus).

Uji instrumen dalam penelitian ini menggunakan uji validitas korelasi momen tangkar (product moment) dan reliabilitas Alpha Cronbach. 
Arah dan besaran perbedaan antara pasangan-pasangan (pra test dan pasca test) dapat ditentukan dan dicocokkan secara hati-hati, maka digunakanlah uji Wilcoxon Matched - Pairs dengan formulasi rumus (Cooper dan Emory Jilid 2, 1999, 275).

$$
\begin{aligned}
& \text { Rata }- \text { rata }=\mu_{T}=\frac{n(n+1)}{4} \\
& \text { Deviasi standar } d=\sigma_{T}=\sqrt{\frac{n(n+1)(2 n+1)}{24}} \\
& \text { Rumus untuk pengujian adalah } z=\frac{T-\mu_{T}}{\sigma_{T}}
\end{aligned}
$$

Selanjutnya hasil uji Wilcoxon Matched - Pairs ini akan dibandingkan dengan uji Pair $t$ tes yang juga menggunakan uji data berpasangan. Nilai $t$ hitung data berpasangan dapat dirumuskan

$$
t=\frac{\bar{D}}{S d / \sqrt{N}}
$$

dimana: $\bar{D}$ adalah perbedaan observasi antara 2 mean. Sd adalah standar deviasi perbedaan observasi pasangan

\section{ANALISA}

Tujuan analisis/penelitian ini adalah untuk menganalisis apakah ada pengaruh "Outbound Management Training" pada potensi terhadap organisasi BI Surabaya sebelum dan sesudah pelatihan. Analisis dilakukan dengan uji Wilcoxon Matched - Pairs untuk menguji hipotesis bahwa dua variabel yang merupakan dua sampel berkaitan mempunyai distribusi yang sama.

\section{Hipotesa:}

- $\mathrm{H}_{0}=$ Pelatihan OMT BI tidak mempunyai pengaruh yang berarti terhadap potensi organisasi.

- $\mathrm{H}_{1}=$ Pelatihan OMT BI mempunyai pengaruh yang berarti terhadap potensi organisasi

Dalam menentukan kriteria penolakan dengan membandingkan nilai $Z_{\text {hitung }}$ dengan nilai $Z_{\text {tabel. }}$.

\section{Kriteria penolakan:}

口 Jika statistik hitung > statistik tabel, maka $\mathrm{H}_{0}$ ditolak.

口 Jika statistik hitung < statistik tabel, maka $\mathrm{H}_{1}$ diterima.

Atau 
- Jika sig. $<0.05$, maka $\mathrm{H}_{0}$ ditolak.

口 Jika sig. > 0.05, maka $\mathrm{H}_{0}$ diterima.

Dengan menjumlahkan seluruh variabel potensi (komitmen, keterbukaan, kecakapan, kebersamaan dan integritas pegawai), berikut ini hasil pengujian dengan uji Wilcoxon Matched - Pairs yang disajikan dengan menampilkan tabel diskripsi, tabel $\mathbf{Z}$ hitung dan gambar $\mathbf{Z}$ normalnya. Selanjutnya data akan diuji dengan menggunakan uji Pair t test, dengan menampilkan tabel statistik t hitung dan gambar distribusi t.

Tabel 1.

Deskripsi Statistik Potensi Secara Keseluruhan

\begin{tabular}{|l|c|c|c|c|c|}
\hline & N & Mean & Std. Deviation & Minimum & Maximum \\
\hline Potensi Pre test & 135 & 485.0741 & 79.6430 & 122.00 & 595.00 \\
\hline Potensi Post test & 135 & 515.8148 & 61.6796 & 284.00 & 627.00 \\
\hline
\end{tabular}

Sumber: Data primer

Tabel deskripsi menggambarkan penyebaran dari data yang dipakai untuk pengujian yang terdiri dari mean (nilai rata-rata data) merupakan satu nilai numerik yang digunakan untuk mewakili semua nilai dalam koleksi data, std. Deviasi (mengukur sebaran diantara nilai rataratanya) merupakan ukuran-ukuran untuk mengevaluasi bagaimana nilainilai berfluktuasi disekitar rata-rata), dan data maximun (nilai tertinggi dari data), minimum (nilai terendah dari data).

Uji Wilcoxon Matched - Pairs untuk menjawab apakah ada pengaruh "Outbound Management Training" pada potensi organisasi pegawai BI Surabaya keseluruhan dari kelima variabel.

Tabel 2.

Tes Statistik Uji Wilcoxon Potensi Secara Keseluruhan

Test Statistics ${ }^{b}$

$\begin{array}{lc} & \begin{array}{c}\text { Potensi Post } \\ \text { test - Potensi } \\ \text { Pre test }\end{array} \\ \text { Z } & -3.111^{\mathrm{a}} \\ \text { Asymp. Sig. (2-tailed) } & .002 \\ \text { a. Based on negative ranks. } \\ \text { b. Wilcoxon Signed Ranks Test }\end{array}$

Sumber: Data primer 
Hasil perhitungan dengan uji Wilcoxon Mantched-Pair didapat sig. $0.002<0.05$, maka $\mathrm{H}_{0}$ ditolak. Z Zitung dapat dibandingkan dengan $Z_{\text {tabel }}$ yang dicari dengan mencari luas kurva normal adalah 50\%-5\%=45\%. Didapat angka $Z_{\text {tabel }}-1.96$. jadi $Z_{\text {hitung }}=-3.111>Z_{\text {tabel }}=-1.96$, maka $H_{0}$ ditolak dan $\mathrm{H}_{1}$ diterima, berarti pelatihan OMT BI Surabaya mempunyai pengaruh terhadap potensi organisasi keseluruhan.

\section{Gambar 1}

\section{Kurva Z hitung Wilcoxon Potensi Organisasi Keseluruhan}

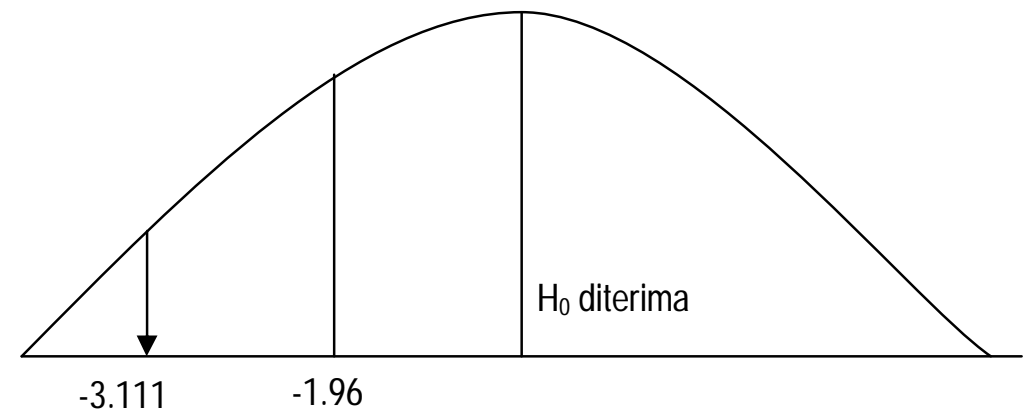

Sehingga dari hasil pengujian hipotesa dapat disimpulkan bahwa pelatihan "Outbound Management Training" Bank Indonesia Surabaya mempunyai pengaruh yang berarti terhadap potensi organisasi secara keseluruhan yang terdiri dari lima variabel yaitu komitmen kepada tugas, keterbukaan dalam bersikap, kecakapan dalam bekerja, kebersamaan dalam hubungan sosial dan integritas pribadi yang tinggi.

Hasil analisa dengan uji Wilcoxon Matched - Pairs akan dibandingkan (bila data dianggap data parametrik) dengan uji Pair $t$ test. Uji Pair $t$ test juga merupakan uji data berpasangan dengan memperhatikan distrubusinya.

\section{Kriteria penolakan:}

a Jika thitung $>\mathrm{t}(\mathrm{n}-1), 5 \%$ tabel, maka $\mathrm{H}_{0}$ ditolak.

口 Jika t hitung $<\mathrm{t}(\mathrm{n}-1), 5 \%$ tabel, maka $\mathrm{H}_{0}$ diterima.

Atau

a Jika sig. $<0.05$, maka $\mathrm{H}_{0}$ ditolak.

口 Jika sig. > 0.05, maka $\mathrm{H}_{0}$ diterima. 
Tabel 3

Tes Statistik Pair $\mathrm{t}$ test Potensi Secara Keseluruhan.

\begin{tabular}{|c|c|c|c|c|c|c|c|c|}
\hline & \multicolumn{5}{|c|}{ Paired Differences } & \multirow[b]{3}{*}{$t$} & \multirow[b]{3}{*}{ df } & \multirow{3}{*}{$\begin{array}{l}\text { Sig. (2- } \\
\text { tailed) }\end{array}$} \\
\hline & \multirow[b]{2}{*}{ Mean } & \multirow{2}{*}{$\begin{array}{c}\text { Std. } \\
\text { Deviation }\end{array}$} & \multirow{2}{*}{$\begin{array}{l}\text { Std. Error } \\
\text { Mean }\end{array}$} & \multicolumn{2}{|c|}{$\begin{array}{l}95 \% \text { Confidence } \\
\text { Interval of The } \\
\text { Difference }\end{array}$} & & & \\
\hline & & & & Lower & Upper & & & \\
\hline $\begin{array}{l}\text { Potensi Pre } \\
\text { test - Potensi } \\
\text { Post Test }\end{array}$ & -30.74 & 107.9200 & 9.2883 & -49.11 & -12.37 & -3.31 & 134 & 001 \\
\hline
\end{tabular}

Hasil perhitungan dan pengujian dengan pair t test ternyata menghasilkan yang juga signifikan, dimana $t_{\text {hitung }}=-3.31>t_{\text {tabel }}=-1.960$, atau dengan sig.0.001<0.05, maka $\mathrm{HO}$ ditolak, berarti secara signifikan pada tingkat signifikansi 5\%, pelatihan OMT BI Surabaya mempunyai pengaruh pada potensi pegawai terhadap organisasi.

\section{Gambar 2}

Kurva Distribusi t Uji Pair t test Potensi Keseluruhan

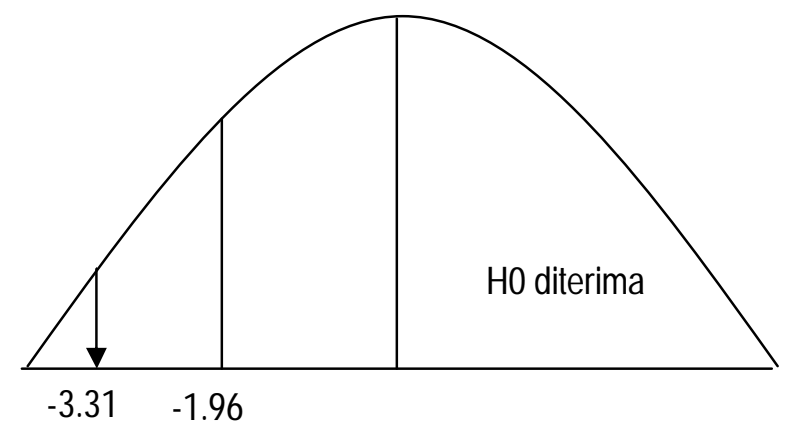

Dengan membandingkan dengan $\mathrm{t}$ tabel two tail test terbukti bahwa hipotesa $\mathrm{H}_{0}$ ditolak yang berarti terdapat pengaruh potensi organisasi setelah pelatihan.

\section{KESIMPULAN}

Hasil pengujian dan analisa dengan menggunakan uji beda berpasangan, antara sebelum dan sesudah pelatihan OMT BI Surabaya baik menggunakan uji Wilcoxon Matched - Pairs dan uji Pair $t$ test dapat disimpulkan sebagai berikut:

1. Potensi pegawai BI Surabaya terbagi menjadi lima variabel pendukung yaitu komitmen, keterbukaan, kecakapan, kebersamaan, dan 
integritas. Dengan menggunakan uji Wilcoxon Matched - Pairs didapat bahwa potensi pegawai mengalami perubahan dan atau terpengaruh secara berarti / signifikan 0.002 pada tingkat signifikansi $5 \%$.

2. Dengan uji Pair t test, didapat bahwa potensi pegawai mengalami perubahan/terpengaruh secara signifikan 0.001 pada tingkat signifikansi $5 \%$.

3. Potensi pegawai mengalami peningkatan rata-ratanya sebelum= 485.0741 menjadi sesudah= 515.8148 dengan adanya pelatihan OMT.

4. Hal ini dapat dikatakan pelatihan OMT telah membawa perubahan meningkat pada potensi pegawai BI Surabaya.

SARAN

1. Untuk meningkatkan potensi, dalam hal ini nilai, sikap dan perilaku yang diinginkan perlu adanya pelatihan dengan metode yang tepat. Outbound Management Training kiranya merupakan jenis metode pelatihan yang tepat, karena menggunakan pendekatan perilaku.

2. Untuk penelitian selanjutnya perlu kiranya melakukan pengukuran pelatihan dengan kategori (Kirk Patric) pada hasil/perilaku. Juga perlu diteliti apakah ada hubungan korelasional antar faktor pada potensi pegawai, serta faktor potensi yang mana yang paling terpengaruh oleh OMT.

\section{DAFTAR PUSTAKA}

Ancok Djamaludin "Outbound Management Training", Aplikasi Ilmu Perilaku Dalam Pengembangan SDM, UII Press Jogjakarta, 2001.

Ancok Djamaludin "Pengembangan Budaya Organisasi Bank Indonesia", 1999 (tidak dipublikasikan).

Azwar Saifudin "Sikap Manusia", Teori dan Pengukurannya, Edisi Kedua, Pustaka Pelajar, Jogjakarta, 2002.

Budaya Kerja Bank Indonesia, Bank Indonesia, Jakarta, 1999 (tidak dipublikasikan).

Clarkc Liz "The Essence of Change", diterjemahkan oleh Muslie Marfin dkk, Edisi Pertama, Andi, Jogjakarta, 1999.

Cooper Donald R., Emory C. William, "Bussiness Research Methods", alih bahasa Ir. Widyono Soetjipto dan Ir. Uka Wikarya, jilid 1 dan 2, Erlangga, Jakarta, 1999.

Dessler Gary "Human Resource Management 7e", Edisi Bahasa Indonesia, jilid 1 dan 2, PT. Prenhallindo, Jakarta, 1997. 
Azwar Saifudin "Sikap Manusia", Teori dan Pengukurannya, Edisi Kedua, Pustaka Pelajar, Jogjakarta, 2002.

Kenna Eugene "The Essence of Human Resource Mabagement", diterjemahkan Santoso Budi Toto, Edisi Pertama, Andi, Jogjakarta, 2002.

Nasution "Manajemen Mutu Terpadu", Ghalia Indonesia, 2001.

Pusat Pelatihan khusus Tanjung Batu, "Pedoman Instruktur", Andersen Consulting.

Robbins Stephen "Perilaku Organisasi", Edisi Indonesia, Jilid 1 dan 2, Prenhallindo, Jakarta, 1996.

Santosa Singgih "SPSS versi 10", Elex Media Komputindo, Jakarta, 2001.

Siagian Sondang "Teori Pengembangan Organisasi", Bumi Aksara, Jakarta, 1997.

Smither Robert "Organization Development", Harper Collins, New York, 1996.

Tjiptono Fandy "Total Quality Management", Edisi Ketiga, Andi, Jogjakarta, 2000. 